\title{
Eventos Extremos de Precipitação no Litoral do Paraná (Baía de Paranaguá)
}

\author{
Ana Cleide Bezerra Amorim ${ }^{1}$ (D), Ada Cristina Scudelari ${ }^{2}$ (D), Cynara Cunha ${ }^{3}$ (D), \\ José Eduardo Gonçalves ${ }^{4}$ \\ ${ }^{\text {I} P r o g r a m a ~ d e ~ P o ́ s-G r a d u a c ̧ a ̃ o ~ e m ~ C i e ̂ n c i a s ~ C l i m a ́ t i c a s, ~ U n i v e r s i d a d e ~ F e d e r a l ~ d o ~ R i o ~ G r a n d e ~ d o ~}$ \\ Norte, Natal, RN, Brasil. \\ ${ }^{2}$ Programa de Pós-Graduação em Engenharia Civil, Departamento de Engenharia Civil, Centro \\ de Tecnologia, Universidade Federal do Rio Grande do Norte, Natal, RN, Brasil. \\ ${ }^{3}$ Programa de Pós-Graduação em Engenharia Ambiental, Departamento de Engenharia \\ Ambiental, Centro de Tecnologia, Universidade Federal do Paraná, Curitiba, PR, Brasil. \\ ${ }^{4}$ Sistema Meteorológico do Paraná, Curitiba, PR, Brasil.
}

Recebido em: 18 de Outubro de 2018 - Aceito em: 26 de Fevereiro de 2020

\begin{abstract}
Resumo
A ocorrência de eventos extremos de precipitação (EEP) no litoral do Paraná eleva o potencial de erosividade dos rios da região, além de causar inundações. Neste contexto, o objetivo deste estudo é analisar a tendência da intensidade e frequência dos EEP diários, além de analisar o ciclo horário dos extremos para a região costeira do Paraná e o ambiente sinótico. Coletaram-se os dados de precipitação e divergência do fluxo de umidade. Consideraram-se EEP diários acima do percentil 95 (EEP95). A análise de tendência linear através do teste Mann-Kendall, análise do ciclo diário e a distribuição espacial do ambiente sinótico foram estudados. Os resultados mostram que os EEP95 não apresentaram tendência significativa. Apesar do estudo limitar-se a uma única localidade, áreas de máxima convergência de umidade destacam o padrão da Zona de Convergência de umidade. Os resultados mostram que o limiar para um EEP95 diário é de 46,40 mm.dia ${ }^{-1}$; apenas durante a madrugada e na estação chuvosa, o ciclo diário dos EEP95 apresentou taxas horárias que atingiram o percentil 95 . O período de janeiro a março, concentrou cerca de 50\% EEP95, com a frequência de EEP95 diminuindo em anos de La Niña e aumentando em anos de El Niño e neutros.
\end{abstract}

Palavras-chave: sul do Brasil, regiões litorâneas, estação chuvosa, precipitação intensa.

\section{Extreme Rainfall Events on the Coastland of Paraná State (Paranaguá Bay)}

\begin{abstract}
The occurrence of extreme precipitation events (EEP) of the coast of Paraná increases the erosivity potential of the rivers in this region, causing flooding among other occurrences. In this context, the objective of this study is to analyze the trends in intensity and frequency of daily EEP, as well as to analyze the extreme hourly cycle for the coastal region of Paraná and the synoptic conditions. Thus, precipitation data and divergence of moisture flow were collected. Daily precipitation above the 95th percentile (EEP95) was considered in this study. From the EEP95, linear trend analysis using the Mann-Kendall test, daily cycle analysis and the spatial distribution of the synoptic environment were studied. Although the study is limited to one locality, areas of maximum moisture convergence highlight the pattern of the Convergence Zone of moisture. The results show that the threshold for a daily EEP95 is $46.40 \mathrm{~mm}$.dia ${ }^{-1}$; only during the early morning and in the rainy season, the daily cycle of the EEP95 presented hourly rates that reached the 95th percentile. The period from January to March, concentrated around 50\% EEP95, with the frequency of EEP95 decreasing in years of La Niña and increasing in years of El Niño and neutral.
\end{abstract}

Keywords: Southern Brazil, coastal region, season wet, extreme events.

Autor de correspondência: Ana Cleide Bezerra Amorim, anacleide23@gmail.com. 


\section{Introdução}

No Brasil, eventos extremos são responsáveis pelo maior número de mortes em termos de desastres naturais (CEPED, 2011). O conceito de desastre utilizado pelo IPCC (2014, AR5) refere-se a eventos relacionados ao clima, impactos físicos ou tendência a estes. Isto é, o IPCC define desastre como sendo: "ocorrência potencial de um evento natural ou fisicamente induzido pelo ser humano, impacto físico ou tendência a este que pode causar perda de vidas, ferimentos ou outros impactos na saúde, bem como perdas e danos à propriedade, infraestrutura, meios de subsistência, prestação de serviços, ecossistemas e recursos ambientais". Os eventos catalogados ao clima, na maioria das vezes estão diretamente ligados a episódio de precipitação intensa. Deste modo, entender a dinâmica da ocorrência de precipitação se encontra cada vez mais em expansão nos últimos anos (Oliveira et al., 2014; 2016; Shimizu et al., 2016).

Os últimos Relatórios Científicos do IPCC (AR4 e AR5) apresentam evidências de mudanças de clima que podem afetar diversas regiões do globo, sobretudo nos extremos climáticos (Silva Dias, 2014). Além disso, o Atlas Brasileiro de Desastres Naturais (CEPED, 2011) mostrou que enxurradas e inundações se apresentaram como os fenômenos mais recorrentes nas Regiões Sul e Sudeste, além dos eventos relacionados a vendavais, granizo e movimentos de massa que também são responsáveis por danos significativos. Percebe-se que esses fenômenos são em geral, acompanhados de eventos extremos de precipitação (EEP), e dependendo da hora que esses eventos ocorrem mais danos à população podem ser contabilizados.

A região litorânea brasileira apresenta grandes centros urbanos, onde se concentram grande parte da população (IBGE, 2014). A maioria dos eventos extremos de precipitação (EEP) ocorrem nestas regiões (Grimm e Tedeschi, 2009). No Nordeste do Brasil (NEB), que apresenta um extenso litoral, Oliveira et al. (2016) constatou a necessidade de dividir o setor oriental do NEB, entre os estados de Rio Grande do Norte e Bahia, em duas subáreas (norte e sul) para estudar EEP. Os resultados evidenciaram a influência de fenômenos de grande escala interanual na frequência dos EEP, em que a máxima frequência se concentrou em anos de La Niña e a mínima em anos de El Niño. Além disso, os ambientes sinóticos associados aos EEP foram diferentes entre o litoral norte e litoral sul, considerando que a estação chuvosa ocorre em períodos diferentes entre as duas áreas. Os fenômenos $E l$ Niño e $L a$ Niña (canônicos) referem-se as fases do ENOS (El Niño Oscilação Sul), em que uma das características apresentadas para o El Niño (La Niña) são as anomalias positivas (negativas) de temperatura da superfície do mar (TSM) no setor leste do Oceano Pacífico. O ENOS é um dos responsáveis pelas alterações interanuais de precipitação em grande parte do globo, incluindo todas as regiões do Brasil. A influência do El Niño e a seca no NEB foi discutida e documentada por Walker (1928). Após 1928, inúmeras pesquisas dedicaram-se ao assunto no NEB (Hastenrath e Heller, 1977; Moura e Shukla, 1981; Alves e Repelli, 1992; Souza e Nobre, 1998; Andreoli e Kayano, 2007; Lucena et al., 2011; Amorim et al., 2014a, 2014b)

Recentemente, a influência de fenômenos de escala intrasazonal também foi discutida em relação a EEP. Shimizu et al., 2016 investigaram EEP secos e úmidos em anos de ENOS e a atuação da oscilação de Madden e Julian (OMJ) na região da Amazônia e NEB durante o período mais chuvoso (dezembro a maio). A OMJ foi discutida na década de 70 por Madden e Julian, que documentaram oscilações com período de 40 a 50 dias. Uma revisão mais recente a respeito desse fenômeno é apresentada em Madden e Julian (1994). As oscilações referidas apresentam um deslocamento para leste de uma célula zonal de grande escala termicamente direta, que dá origem a mudanças na convecção tropical. Os resultados de Shimizu et al., 2016 evidenciaram que eventos extremos secos sobre o NEB são mais frequentes em anos de $E l$ Niño e a presença de convecção OMJ, localizada na Indonésia e Pacífico Ocidental/ausência de convecção sobre o NEB. Em contrapartida, EEP úmidos são mais frequentes durante os anos de La Niña (e neutros) e fases da MJO em que há supressão de convecção sobre a Indonésia/convecção sobre o NEB. Neste estudo, o número de EEP úmidos com MJO ativo apresentou $60 \%$ superior em relação a MJO inativo.

Os EEP ocorrem pela interação de vários fenômenos meteorológicos presentes em diferentes escalas de tempo e espaço, e são mais frequentes na estação chuvosa da região. A região Sul do Brasil não apresenta uma estação chuvosa bem definida (Rao e Hada, 1990), portanto, EEP podem ocorrer ao longo do ano na região (Teixeira e Satyamurty, 2007). A região Sul é exposta, com maior frequência, a eventos extremos chuvosos do que a eventos extremos secos (Altamirano, 2010). Além disso, estudos mostraram evidências de tendências positivas significativas da precipitação total anual na segunda metade do século XX, em grande parte da região Sul do Brasil (Liebmann et al., 2004; Obregón e Marengo, 2007).

Os EEP podem causar grandes transtornos (Souza et al., 2012), tais como, interdição de trechos de rodovias nacionais e estatuais por rompimentos de asfalto, alagamentos, deslizamento de encostas, entre outras ocorrências que afetam diretamente a população. Em 11 de março de 2011, depois de uma sequência de dias chuvosos, várias cidades costeiras do estado do Paraná sofreram com o deslizamento de encostas, enchentes e desabamento de pontes. Comunidades ficaram isoladas, ruas foram alagadas, pedras rolaram dos morros, entulhos carregados pela correnteza causaram graves problemas nas vias de ligação entre o litoral e o interior do Estado. Entre os dias 10 e 12 
de março de 2011, a estação de Morretes registrou $537 \mathrm{~mm}$ de chuva e a estação de Antonina, entre os dias 10 e 13 do mesmo mês, registrou $380 \mathrm{~mm}$; valores muito acima da média para o mês de março (Lopes e Souza, 2012).

Os vários rios que drenam a bacia hidrográfica do litoral paranaense apresentam grande declividade, conferindo um alto potencial erosivo. A região de ocorrência de EEP eleva mais o potencial de erosividade destes rios. O excesso de sedimento movimentado durante estes eventos extremos se deposita na baía de Paranaguá, alimentando o sistema com sedimentos finos, favorecendo a sua deposição. A baía de Paranaguá possui dois portos (de Paranaguá e Ponta do Félix), e a manutenção dos canais de navegação de acesso aos portos por meio das operações de dragagens, constitui uma atividade onerosa e impactante para o meio ambiente. Entre os dois portos, encontra-se uma zona com elevadas concentrações de sedimentos em suspensão, indicando o possível local onde os sedimentos provenientes dos rios ficam retidos, até a sua deposição final (Cunha et al., 2015).

Neste contexto, o objetivo principal deste estudo é analisar a tendência da intensidade e frequência dos eventos extremos de precipitação diários, identificar o seu ambiente sinótico, além de analisar o ciclo horário dos extremos para a região costeira do Paraná e assim contribuir no gerenciamento de regiões sujeitas a eventos extremos, considerando que tais eventos possuem a capacidade de elevar as vazões líquidas dos rios e que o volume de material particulado em suspensão, associados a esta elevação das vazões, deverão depositar ou ficar retido na zona de máxima turbidez da baía de Paranaguá, contribuindo para o assoreamento desta região.

\section{2. Área de estudo}

O estado do Paraná apresenta a faixa litorânea banhada por águas do Oceano Atlântico Sul. No litoral paranaense encontram-se os municípios Guaraqueçaba, Antonina, Morretes, Paranaguá, Matinhos, Guaratuba e Pontal do Paraná, dos quais as quatro primeiras cidades pertencem à bacia de contribuição da baía de Paranaguá. A baía de Paranaguá (Fig. 1) abriga um dos mais importantes portos do país em importância econômica para o Brasil, o porto de Paranaguá, e apresenta um berço de riquezas de inúmeras variedades de espécies da fauna e flora (Lana et al., 2000).

O clima da região é classificado como subtropical úmido (Alvares et al., 2013), com período de chuvas durante todo o ano. Os ventos são predominantes da direção ENE, E, ESE e SE, com intensidade média de $4,0 \mathrm{~m} \cdot \mathrm{s}^{-1}$ (Camargo e Marone, 1995). As montanhas da Serra do Mar atuam como barreira aos sistemas de circulação atmosférica e à penetração das massas de ar úmidas provindas do Atlântico Sul resultando na concentração de frentes estacionárias na região das baías (Lana et al., 2000).

A distribuição anual das chuvas na região Sul do Brasil se faz de forma bastante uniforme. Ao longo de quase todo seu território a média anual da precipitação varia de 1250 a $2000 \mathrm{~mm}$. Somente algumas áreas encontram-se fora desse limite pluviométrico. Entre estas se
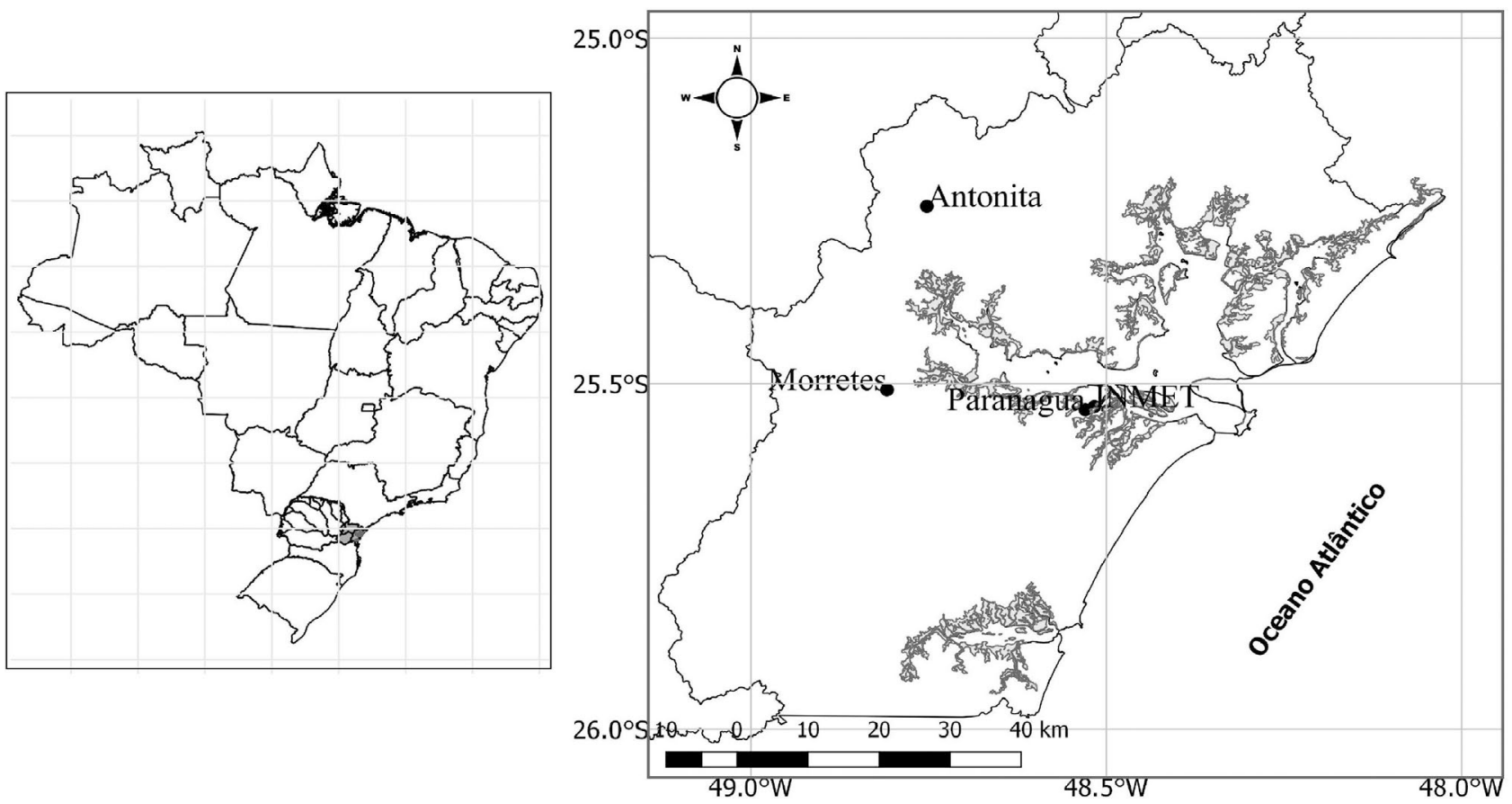

Figura 1 - Localização da região de estudo. 
incluem o litoral do Paraná, que apresenta precipitação anual acima de $2000 \mathrm{~mm}$ (Alvares et al., 2013).

Especificamente, no estado do Paraná a estação de verão é climatologicamente chuvosa. As frentes frias que se deslocam pela Região Sul ocasionam chuvas (Olivera, 1986; Cavalcanti e Kouski, 2009) durante a estação de verão, no entanto outro sistema meteorológico comum é o complexo convectivo de mesoescala (CCM) que favorecem as chamadas "chuvas de verão" (Grimm, 2009). A precipitação média anual do litoral paranaense é de $2500 \mathrm{~mm}$ (Alvares et al., 2013), com taxas pluviométricas três vezes maiores no período de maior chuva.

Os Boletins Climáticos do Paraná (SIMEPAR, 2019) narram que as chuvas na estação de outono são decorrentes, principalmente, da passagem de sistemas frontais, que possuem como característica uma distribuição mais regular. No inverno é marcado pelos eventos frequentes de geadas, decorrentes do deslocamento das massas de ar frio. As massas de ar frio favorecem uma longa estabilidade atmosférica, o que provoca a diminuição das chuvas ao longo da estação, ou seja, é a estação onde o volume de chuva é menor. Na primavera (SON), o estado do Paraná é marcado pelo aumento das temperaturas e de ocorrências de pancadas de chuvas favorecidas por sistemas convectivos, que se tornam mais frequentes durante esta estação.

\section{Materiais e Métodos}

A Fig. 2 apresenta o fluxograma da metodologia proposta. Inicialmente, coletaram-se os dados de precipitação em duas escalas de tempo, horário e diário, além de dados de divergência do fluxo de umidade. A primeira fonte de dados observados de precipitação apresenta escala diária e pertencem ao Órgão oficial de Meteorologia no Brasil, o Instituto Nacional de Meteorologia (INMET), representante brasileiro junto à Organização Mundial de Meteorologia (OMM). A outra fonte possui taxas horárias e pertence ao Sistema Meteorológico do Paraná - SIMEPAR, que mantém uma rede de estações meteorológicas de superfície em todo o estado. Os dados de divergência de fluxo de umidade, da Era-Interim, destacaram-se os valores negativos.

Aos dados do INMET, aplicou-se a técnica dos quantis para se conhecer o limiar de um EEP diário. A partir da seleção dos EEP surgiram os principais resultados, a análise de tendência (frequência e intensidade), análise do ciclo diário de EEP, utilizando os dados horários das estações do SIMEPAR, e a distribuição espacial do ambiente sinótico referente aos EEP.

\subsection{Dados}

Utilizaram-se duas fontes de precipitação in situ do munícipio de Paranaguá (INMET e Paranaguá), Fig. 1. A primeira contém 30 anos $(01 / 01 / 1986$ a 31/12/2016) da estação meteorológica do INMET, localizada na latitude $25,53^{\circ} \mathrm{S}$ e longitude $48,51^{\circ} \mathrm{W}$, com altitude de $48,51 \mathrm{~m}$.

A segunda fonte de dados de precipitação apresenta taxas horárias do período de 21/11/2012 a 14/07/2017. Essa estação faz parte da rede de estações de superfície mantidas pelo SIMEPAR. Os dados gerados por essa estação e por toda a rede de monitoramento são utilizados em sistemas operacionais de previsão de tempo, estimativas de afluências a reservatórios de hidroelétricas localizadas na bacia do Rio Iguaçu, emissão de alertas de eventos severos. Além disso, esses dados se encontram disponíveis para o desenvolvimento de pesquisas acadêmicas. A localização desta estação encontra-se entre as coordenadas $25,53^{\circ} \mathrm{S}$ e longitude $48,53^{\circ} \mathrm{W}$ (Fig. 1).

O campo do fluxo de umidade integrada na vertical foi obtido das reanálises do modelo global do European Centre for Medium Range Forecasting (ECMWF), especificamente, usou-se informações do produto ERA-Interim (Dee et al., 2011; Berrisford et al., 2011), também para o

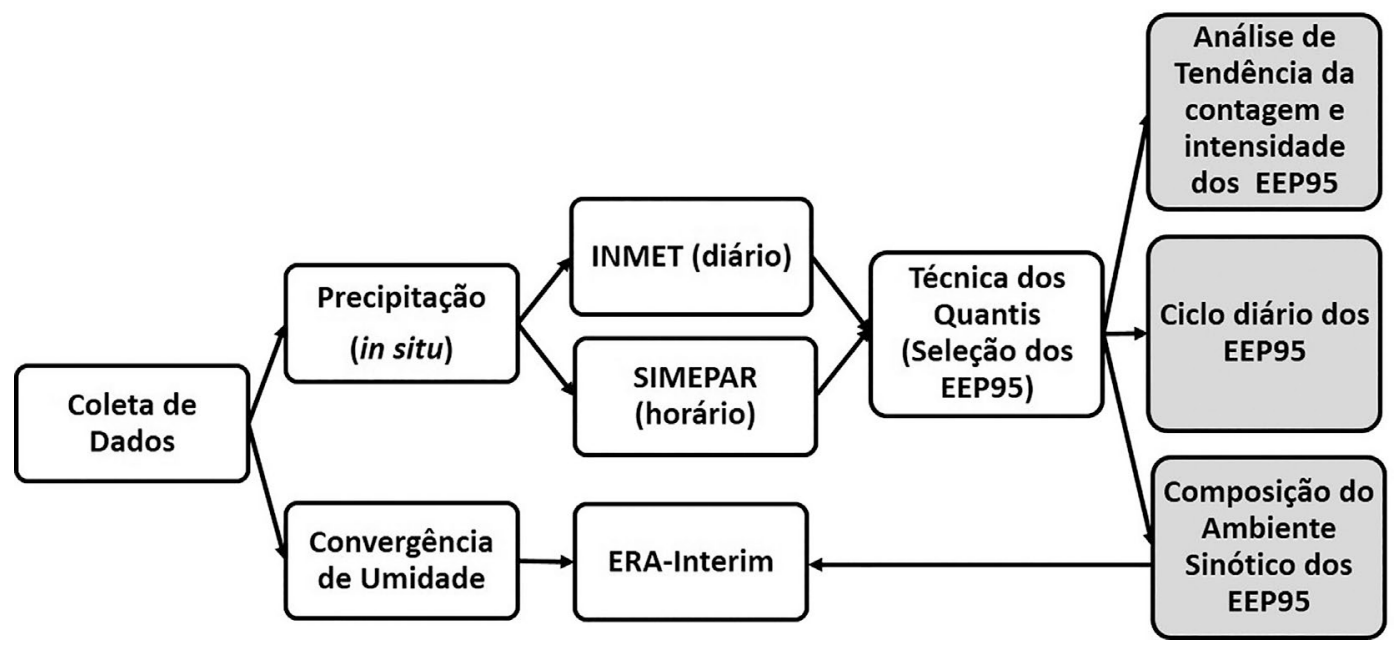

Figura 2 - Fluxograma com a metodologia proposta neste estudo. 
período de 1986 a 2016 , numa grade de $1,5^{\circ}$ x $1,5^{\circ}$ de latitude por longitude. A divergência do fluxo de umidade foi avaliada entre a superfície e $300 \mathrm{hPa}$. Destacaram-se os valores negativos da divergência da umidade para discussão dos resultados.

\subsection{Eventos extremos de precipitação}

Antes de identificar o limiar para um EEP diário da estação meteorológica de Paranaguá, verificou-se ausência de $7,7 \%$ de dados, no qual se refere aos anos de 1993, 1999 e 2001 com $60 \%$ dos dias ausentes. Semelhante a Texeira e Satyamurty, 2011 que realizaram um estudo de EEP para o Sul e Sudeste do Brasil considerando ausência de dados abaixo de $10 \%$, não foi feito procedimento para completar as séries temporais. Constatou-se também a presença de $49 \%$ dos dias sem ocorrência de precipitação. Desta forma, foi aplicada a técnica dos quantis (Wilks, 2006) apenas aos $51 \%$ dos dias com precipitação diária maior que zero.

A técnica dos quantis é comumente usada para estudos de EEP (Costa et al., 2015; Oliveira et al., 2016; Shimizu et al., 2016). Os eventos diários de chuva $(\geq 0,1)$ partiram com base no percentil (Wilks, 2006) da distribuição de precipitação da estação meteorológica de Paranaguá do INMET, nos quais se consideraram EEP aqueles com precipitação diária acima do percentil 95 (Oliveira et al., 2016) durante 1986 a 2016, chamados de EEP95.

\subsubsection{Análise de tendências}

Utilizou-se para análise da tendência linear o teste não-paramétrico Mann-Kendall (Mann, 1945; Kendall, 1975). Aplicou-se o teste apenas para a frequência e intensidades dos EEP95 anual e estação chuvosa durante o período de 1986 a 2016. O uso do teste Mann-Kendall (MK) é comum para determinar as tendências em variáveis do clima (Gocic e Trajkovic, 2013; Costa et al., 2015; Luiz Silva et al., 2015; Oliveira et al., 2016). O teste de MK é calculado a seguir:

$$
S=\sum_{j=1}^{n-1} \sum_{i=2}^{n} \operatorname{sinal}\left(x_{i}-x_{j}\right)
$$

O valor do $S$ é obtido através da soma de todas as contagens da série de dados, onde $x_{i}$ e $x_{j}$ correspondem aos valores da série (anual ou sazonal) nos anos $i$ e $j$, respectivamente. O sinal é obtido através de:

$$
\text { sinal }=\left\{\begin{array}{rc}
1, & \text { se }\left(x_{i}-x_{j}\right)>0 \\
0, & \text { se }\left(x_{i}-x_{j}\right)=0 \\
-1, & \text { se }\left(x_{i}-x_{j}\right)<0
\end{array}\right.
$$

Quando $n$ é alto, $S$ tende a normalidade e variância definida através:

$$
\begin{aligned}
\operatorname{VAR}(S) & =\frac{1}{18}[n(n-1)(2 n+5) \\
& \left.-\sum_{p=1}^{q} t_{p}\left(t_{p-1}\right)\left(2 t_{p}+5\right)\right]
\end{aligned}
$$

onde $t_{p}$ representa o número de dados com valores iguais em certo grupo e q a quantidade de grupos de valores iguais na série de dados em um grupo $p$. O teste estatístico de Mann Kendall é dado pela Eq. (4):

$$
Z_{M K}=\left\{\begin{array}{cr}
\frac{s-1}{\sqrt{V A R(S)}}, & \text { se } S>0 \\
0, & \text { se } S=0 \\
\frac{s+1}{\sqrt{V A R(S)}}, & \text { se } S<0
\end{array}\right.
$$

$\mathrm{O}$ valor $Z_{M K}$ permitiu o cálculo da tendência com significância estatística de 5\%.

\subsubsection{Composição dos eventos de extremos}

Após a triagem dos EEP95 diário, construiu-se a composição dos dias dos EEP95. O objetivo foi identificar os sistemas meteorológicos associados aos extremos. A composição de uma variável é obtida por meio da Eq. (5):

$$
\bar{\varnothing}(x, y, p, D)=\frac{1}{N_{u}} \sum_{j=1}^{N_{u}} \varnothing(x, y, p, j, D)
$$

em que Ø é a variável da composição (acumulado de precipitação diário); $(x, y, p)$ representa as coordenadas espaciais da variável; $N_{u}$ é número de EEP95; $D$ é o dia do EEP95 e o índice $j$ é o $j$-ésimo EEP95.

Realizou-se a composição da divergência de umidade para os dias dos EEP95.

\subsection{Análise horária dos EEP95}

A análise do ciclo diário dos EEP95 partiu dos dados da estação do SIMEPAR. A análise horária se limitou a estudar os extremos de chuva no período dos últimos cinco anos, 2012-2017. Utilizou-se a metodologia de Trenberth et al. (2017) que apresenta a taxa de precipitação média horária $\left(\mathrm{mm} \cdot \mathrm{h}^{-1}\right)$. Seja $P_{i, n}$ a taxa de precipitação para $i=1, \ldots, 24$ horas, no dia $n=1,2, \ldots, N$, no qual $N$ é o número de EEP95 dos cinco anos. A taxa média diária é

$$
\bar{P}_{n}^{24}=\frac{1}{24} \sum_{i=1}^{24} P_{i, n}
$$

A média de todos os EEP95 para cada hora $i$ é

$$
\overline{\bar{P}}_{i}=\frac{1}{N} \sum_{n=1}^{N} P_{i, n}
$$

As Eqs. (6) e (7) foram contabilizadas mensalmente, dando ênfase a estação chuvosa do município de Paranaguá. 


\section{Resultados e Discussão}

Primeiramente, os resultados partiram dos dados observados de precipitação da estação do INMET, no qual se verificou o percentual de dados ausentes e a climatologia do munícipio de Paranaguá. Em seguida, conheceu-se o limiar para um EEP95 diário, sendo possível analisar a tendência da frequência e intensidade nos últimos 30 anos, além da composição do ambiente sinótico referente aos EEP95. Os dados de precipitação do SIMEPAR permitiram a verificação do ciclo horário dos EEP95 nos cinco anos.

\subsection{Climatologia de precipitação}

A Fig. 3 exibe o gráfico do boxplot, no qual é formada pelo primeiro e terceiro quartil, a mediana, além da média aritmética (círculos fechados). Através da média pode-se verificar que o período chuvoso de Paranaguá cobre meses da estação de verão (janeiro e fevereiro), além do mês de março. Desta forma, optou-se pelo uso da estação chuvosa, janeiro a março (JFM), para as análises. Na temporada de chuva no litoral paranaense predomina o regime de monções de verão (Grimm, 2009), com máximos de precipitação nos meses de janeiro, fevereiro e março. A precipitação mensal na estação chuvosa apresenta alta variabilidade, inclusive os meses de janeiro e fevereiro destacam-se com maior dispersão nos valores de chuva durante o período de estudo. Nos demais meses do ano, em especial no semestre mais frio de maio a setembro, a precipitação é influenciada por condições baroclínicas que proporcionam frequentes ciclogêneses e maior penetração de frentes, embora as ondas baroclínicas trafeguem em latitudes médias, no inverno essa circulação penetra nos sub-trópicos favorecendo a formação de precipitação (Grimm, 2009).

\subsection{Eventos extremos de precipitação}

A técnica dos percentis aplicada aos dados de precipitação diária (período de 1986 a 2016) identificou o percentil 95 com valor de 46,40 mm.dia ${ }^{-1}$.

A Fig. 4 apresenta a distribuição mensal dos acumulados de precipitação diários em Paranaguá de 1986 a 2016. Totalizaram-se duzentos e sessenta e cinco (265) eventos de precipitação que ultrapassaram o valor $46,40 \mathrm{~mm} \cdot \mathrm{dia}^{-1}$, no qual 50,90\% (135) ocorreram durante os meses de janeiro a março.

Os registros de EEP95 são consistentes com a climatologia de precipitação (Fig. 3), no qual o maior número de episódios EEP95 concentrou-se no período chuvoso, principalmente, nos meses de janeiro e fevereiro, ambos com 51 eventos. Destaca-se que os dois EEP95 de maior volume ocorreram no mês de janeiro, 295,80 (84,60\% da média mensal, Fig. 3) e 202,90 mm.dia ${ }^{-1}$.

O número de EEP95 diminui a partir do mês de abril, no entanto ainda foram observados no litoral paranaense episódios intensos (valores cinza, Fig. 4), e o mês de agosto apresentou a menor frequência mensal com apenas 3 ocorrências, conforme constatado por Teixeira e Satyamurty, 2007 que afirmam que a ocorrência de EEP95 na Região Sul do Brasil são comuns durante todo o ano.

A Fig. 5 apresenta a variabilidade anual (coluna cinza) e trimestral (coluna preta) dos EEP95 em Paranaguá. Os trimestres são janeiro a março (JFM), abril a junho (AMJ), julho a setembro (JAS) e outubro a dezembro (OND). Destacam-se nos anos de 1995 e 2010 as maiores

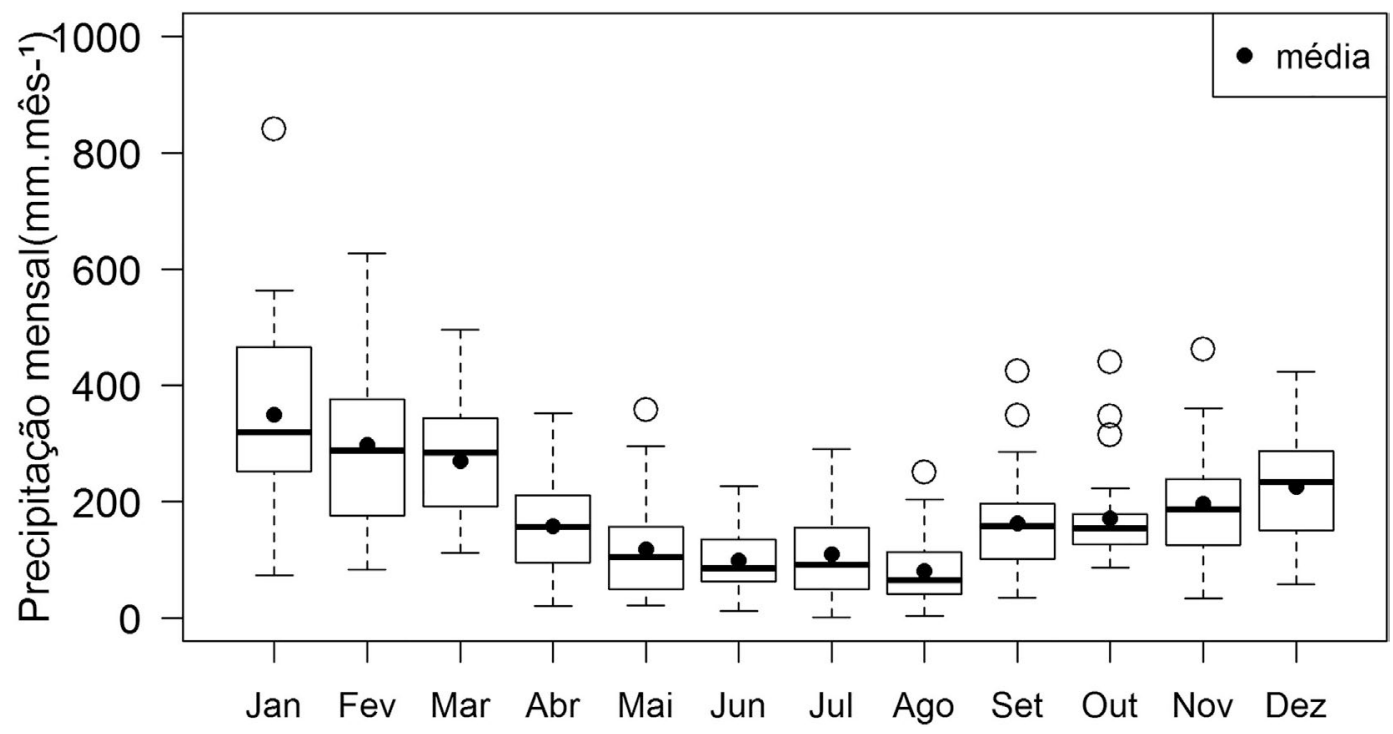

Figura 3 - Distribuição da precipitação mensal de Paranaguá, em mm, para o período de 1986 a 2016. Os círculos fechados representam a média mensal de precipitação. Fonte: INMET. 


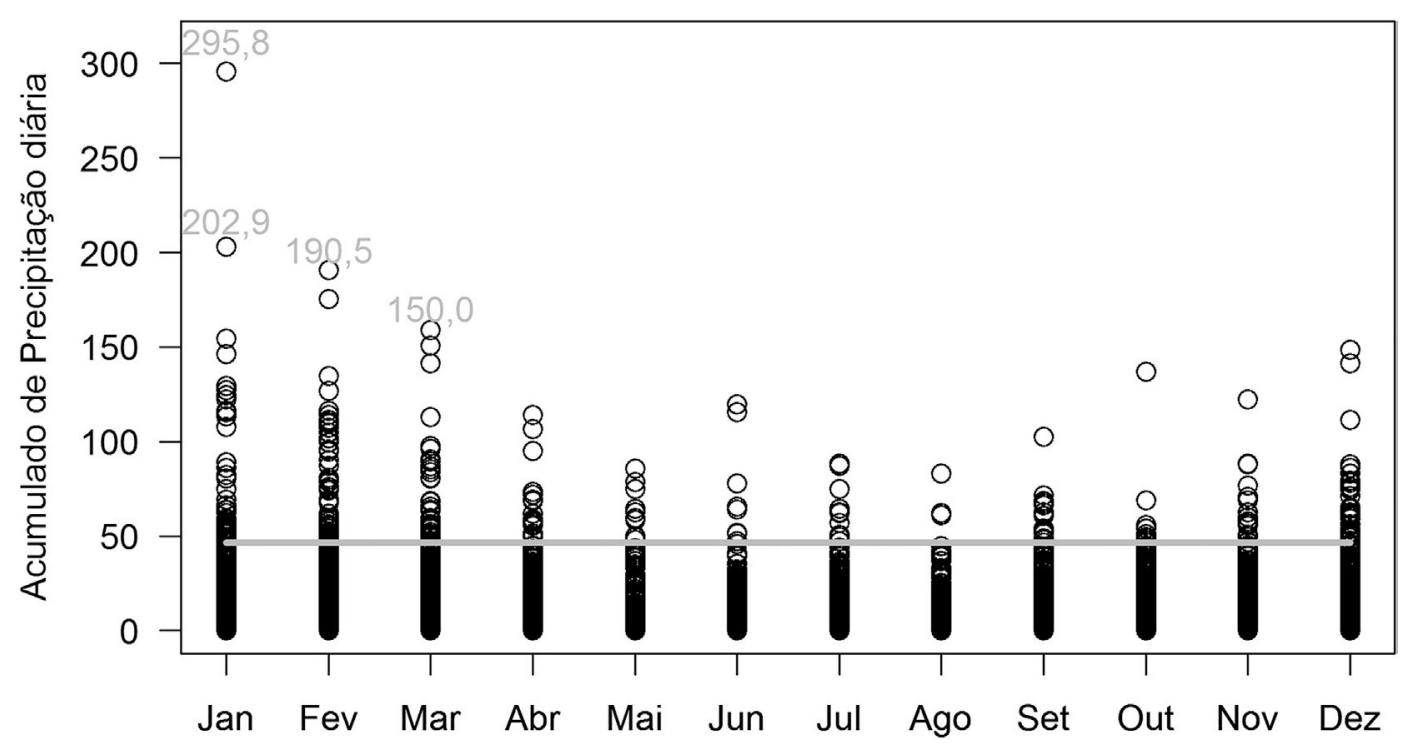

Figura 4 - Distribuição mensal do acumulado de precipitação diária do INMET em Paranaguá-PR (círculos) durante o período de 1986 a 2016. A linha cinza representa o valor do percentil $95\left(46,40 \mathrm{~mm} \cdot \mathrm{dia}^{-1}\right)$ e os números na parte superior o maior registro de EEP95.
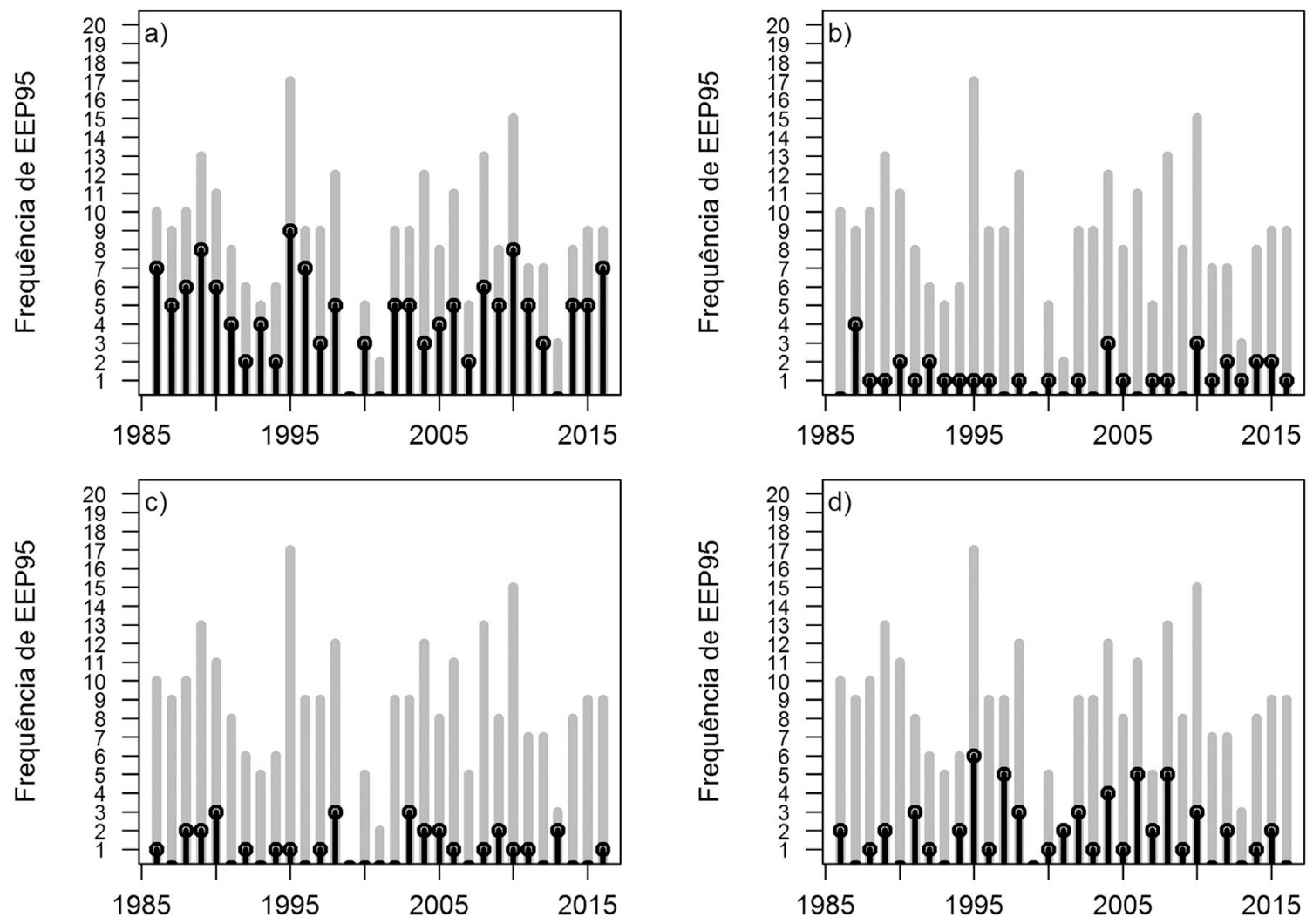

Figura 5 - Frequências (anual e trimestral) de EEP95 no município de Paranaguá-PR cobrindo o período de 1986 a 2016: a) JFM; b) AMJ; c) JAS; d) OND. A barra preta representa a frequência em cada trimestre e a barra cinza a frequência anual.

frequências anuais de episódios, dezessete e quinze, respetivamente. O trimestre chuvoso (Fig. 5a) apresenta as maiores frequências em relação aos demais trimestres. O ano de 1995 apresentou $52,90 \%$ dos EEP95 nos meses de janeiro e fevereiro (Fig. 5a), e no mês de março não apre- sentou registro de extremo. Em 2010, 53,30\% dos EEP95 ocorrem ao longo do trimestre chuvoso. Em contrapartida, no ano de menor frequência, 2013, nenhum EEP95 foi registrado na estação chuvosa. Os três registros foram nos meses de inverno austral. 
Os resultados revelaram uma possível influência em relação a anos de ENOS, onde os dois anos de maiores frequências anuais de EEP95 no município de Paranaguá consistem em temporadas de fenômenos El Niño. Deste modo, uma breve abordagem a respeito do ENOS para a estação de Paranaguá foi realizada em relação a frequência de EEP95 com ênfase na estação chuvosa. O padrão no oceano Pacífico durante o ano de 1994/1995 e 2009/2010 sugeria o favorecimento do aumento da precipitação em grande parte do Sul do Brasil (Grimm e Tedeschi, 2009).

A Tabela 1 exibe os anos de La Niña, El Niño e neutro (NOAA/Climate Prediction Center - CPC, 2017). Estudos anteriores mostraram evidencias que os episódios de ENOS (El Niño e La Niña) influenciam mais na frequência de EEP em várias regiões da América do Sul (Grimm e Tedeschi, 2009; Oliveira et al., 2016), e sendo assim, a discussão limitou-se a frequência dos EEP95.

Especificamente para Paranaguá, calcularam-se as frequências por temporada de ENOS através do somatório dos EEP95 de todos os anos, de janeiro a março do ano seguinte ao início do episódio. Episódios de El Niño canônicos (La Niña) são identificados na região do Niño 3.4 durante os meses de novembro a fevereiro, através de anomalias de TSM maiores ou iguais a $0,5{ }^{\circ} \mathrm{C}$ (menores ou iguais a $-0,5{ }^{\circ} \mathrm{C}$ ) considerada a fase madura do ENOS (Trenberth, 1997). O índice 3.4, além de apresentar melhores correlações com as anomalias de precipitação sobre a América do Sul (especificamente no norte e sudeste da América do Sul, envolvendo o Sul do Brasil), influencia o clima do Sul do Brasil entre zero e dois meses de defasagem após o início de um El Niño ou La Niña (Chen e Chung, 2015). Os resultados mostraram menor frequência dos EEP95 nos anos de La Niña (32), sendo que em temporadas de $E l$ Niño e neutro a frequência atingiu próximo ao dobro (58 e 49, respectivamente) em relação aos anos de La Niña.

Em relação as maiores frequências anuais de EEP95 (acima de dez eventos por ano) ocorreram em anos de $E l$ Niños e anos neutros, e apenas um ano de La Niña a frequência apresentou-se elevada, no ano de 1989.

A Fig. 6 apresenta a intensidade dos EEP95 do período de 1986 a 2016, anual (Fig. 6a) e JFM (Fig. 6b). Estudos anteriores em termos anuais e mensais mostraram que áreas da Região Sul do Brasil destacam-se com tendências positivas significativas de precipitação (Texeira e Satyamurty, 2011; Pinheiro et al., 2013), em especial, a faixa leste do centro do Rio Grande do Sul até o Paraná (Silva et al., 2010), porém os resultados aqui apresentados não mostram tendência com significância estatística para o município de Paranaguá.

Os resultados revelaram que os eventos extremos em Paranaguá não se apresentaram mais intensos nos últimos trinta anos, e quanto à frequência de ocorrência de EEP95 diário no litoral, também não expõe resultados significativos.

Especificamente, o estado do Paraná desde meados do século XX vem sofrendo uma tendência de positiva no volume pluviométrico nos meses de verão e de primavera (Minuzzi e Caramori, 2011). Pinheiro et al., 2013 analisaram dados de chuva com amostras superiores a 40 anos da Região Sul do Brasil, evidenciando nas séries mensais e anuais tendências estatisticamente significativas ao nível de $5 \%$ de aumento dos totais precipitados para o período analisado. Inclusive, destacaram o mês de janeiro com tendência de aumento em todas as estações pluviométricas do Paraná, exceto na estação de Foz do Iguaçu.

Apesar dos estudos de Pinheiro et al., 2013 apresentarem tendências positivas para o litoral paranaense, neste estudo nenhuma tendência foi verificada. Porém, deve-se observar o fato que a estação utilizada por Pinheiro et al., 2013 está a $40 \mathrm{~km}$ do município de Paranaguá (Morretes - PR), e também que as escalas de tempo usadas no estudo são diferentes. Além disso, detectar um EEP95 ainda é influenciado pela carência da distribuição espacial de dados, por séries curtas de dados diários, falhas existentes etc.

\subsection{Aspectos sinóticos dos EEP95}

A convergência do fluxo de umidade sobre o sul do Brasil é um fator importante para a precipitação (Texeira e Satyamurty, 2011). A Fig. 7 ilustra apenas a composição da divergência do fluxo de umidade. A convergência em baixos níveis dá origem a movimentos verticais ascendentes, favorece o desenvolvimento de nuvens e, portanto, precipitação dada à disponibilidade de umidade.

Nos meses de JFM (Fig. 7a) verifica-se uma banda de valores negativos representativo da máxima convergência de umidade com orientação noroeste-sudeste, desde o sul da Amazônia até o litoral da Região Sul e Sudeste do Brasil. Essa região deve-se a presença de uma Zona de Convergência de Umidade (ZCOU) ou Zona de Convergência do Atlântico Sul (ZCAS) (Carvalho et al., 2002, 2004). Uma das características das Zonas de Convergências são exatamente regiões de escoamento convergente e fortes movimentos ascendentes do ar (Kodama, 1992). Primeiramente, a ZCOU é identificada, e após três

Tabela 1 - Anos de ocorrências de ENOS e anos neutros.

\begin{tabular}{lccc}
\hline Nino 3.4 & La Niña & El Niño & Neutro \\
\hline Temporada & $1988 / 89^{*}, 1995 / 96^{*}, 1998 / 99^{*}$, & $1986 / 87^{*}, 1987 / 88^{*}, 1991 / 92^{*}, 1994 / 95^{*}, 1997 /$ & $1985 / 86^{*}, 1989 / 90^{*}, 1990 / 91^{*}, 1992 / 93^{*}, 1993 / 94^{*}$, \\
& $1999 / 00^{*}, 2000 / 01^{*}, 2007 / 08^{*}$, & $98^{*}, 2002 / 03^{*}, 2004 / 05^{*}, 2006 / 07^{*}, 2009 / 10^{*}$, & $1996 / 97^{*}, 2001 / 02^{*}, 2003 / 04^{*}, 2005 / 06^{*}, 2008 / 09^{*}$, \\
& $2010 / 11^{*}, 2011 / 12^{*}$ & $2014 / 15^{*}, 2015 / 16^{*}$ & $2012 / 13^{*}, 2013 / 14^{*}$ \\
\hline
\end{tabular}

${ }^{*}$ ano seguinte ao início do ENSO. 

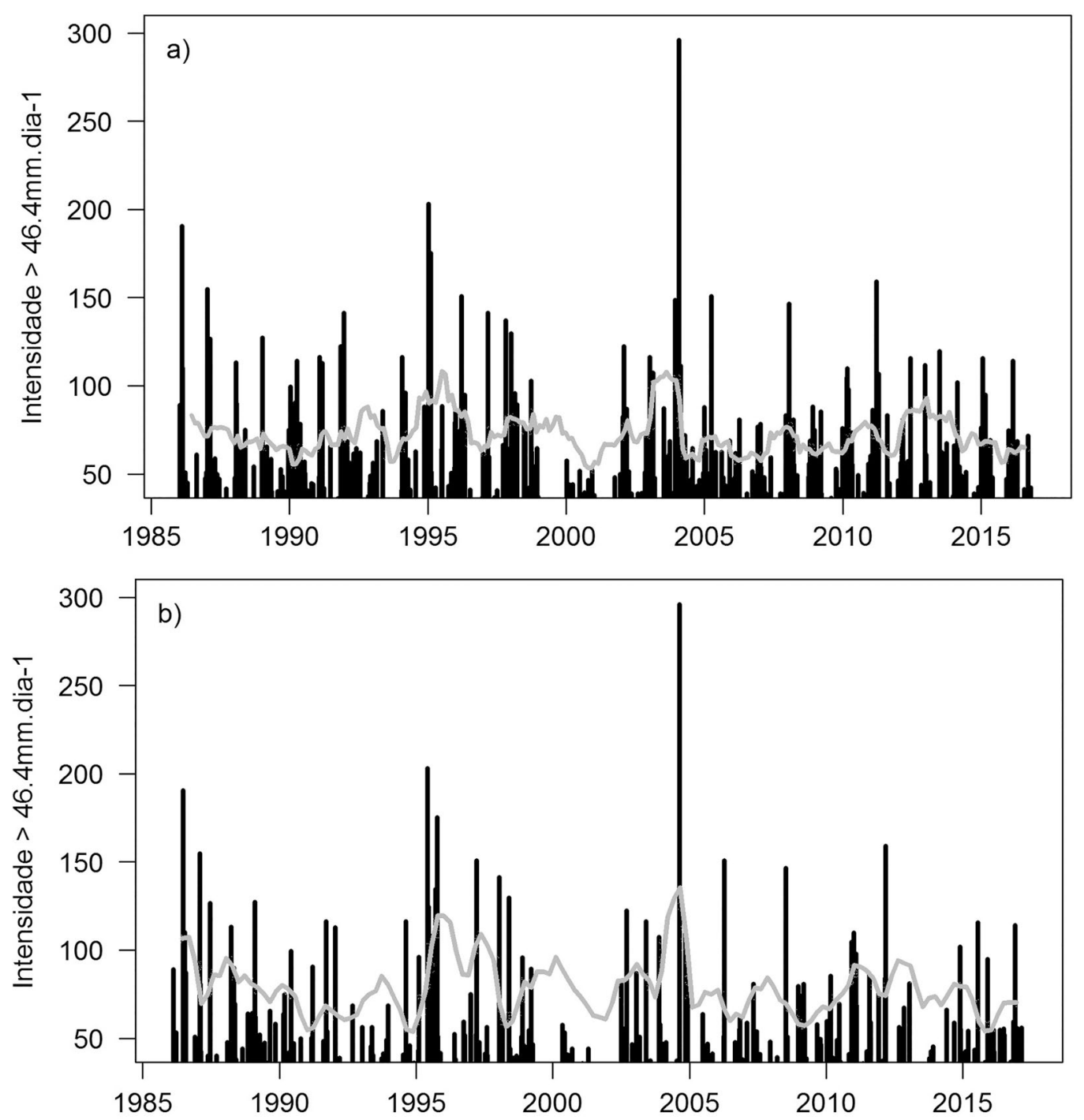

Figura 6 - Variabilidade da intensidade dos eventos EEP95 no município de Paranaguá: a) anual e b) JFM.

dias de atuação ou mais passa a ser chamada de ZCAS. Reboita et al., 2012 destacam a importância da ZCAS e ZCOU à elevados totais de precipitação sobre a região em que se encontram organizadas.

O padrão de ZCAS (ou ZCOU) também associa a presença de um dipolo de anomalias de precipitação entre áreas das regiões Sul e Sudeste (Grimm, 2009). A composição dos dias dos EEP95 evidenciou este comportamento, onde áreas de divergência de umidade cobrem grande parte da região Sul (Rio Grande do Sul, sul e oeste de Santa Catarina e sudoeste do Paraná) caracterizando um ambiente desfavorável à ocorrência de precipitação, e a convergência já mencionada sobre a Região Sudeste do Brasil e litoral leste do Paraná.

Especificamente, no Paraná constatam-se áreas de máxima convergência de umidade apenas nas regiões norte e leste, onde o núcleo mais intenso apresentou valores semelhantes aos encontrados sobre a região Ama- zônica. A região Amazônica, por estar localizada numa área de floresta tropical úmida pode apresentar mais umidade que o Sul do Brasil. No entanto, o Oceano Atlântico Sul abastece a região leste do Paraná com vapor d'água, fazendo com que os valores de convergência de umidade apresentem-se semelhantes.

Apesar da limitação deste estudo aos EEP95 de uma única localidade (da série de dados de Paranaguá), áreas de máxima convergência de umidade destacaram-se não só na faixa leste do Paraná, mas em áreas como o nordeste de Santa Catarina e sul de São Paulo (Fig. 7b). Santo e Satyamurty, 2002 analisando episódios de chuvas intensas na região Sudeste do Brasil e adjacências no período de cinco anos (1997 a 2001), destacaram o município de Paranaguá, com maior número de dias de chuva.

Além disso, Reboita et al., 2012 também destacam que, a faixa litorânea da região Sul/Sudeste do Brasil, é uma região favorável a formação de ciclones. Estes auto- 


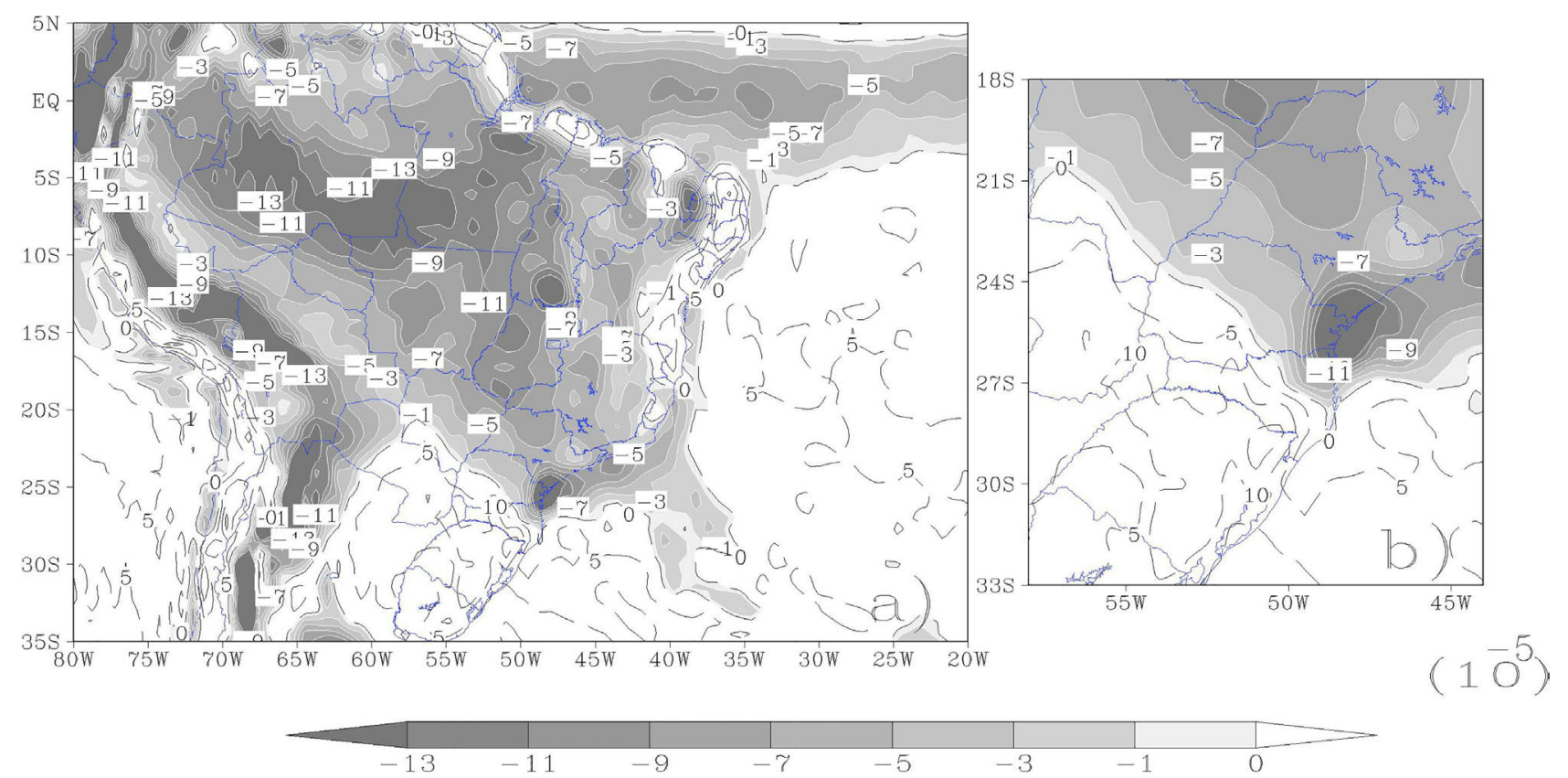

Figura 7 - Composição da divergência de umidade $\left(10^{-5} \mathrm{~kg} . \mathrm{s}^{-1}\right)$ dos EEP95 do município de Paranaguá-PR, cobrindo o período de 1986 a 2016 para os meses JFM: a) Brasil e b) Região Sul e parte do Sudeste do Brasil. Os valores negativos representam a convergência de umidade.

res ressaltam a ocorrência de ventos fortes, precipitação e diminuição da temperatura na formação desses sistemas meteorológicos. No entanto, o estudo limitou-se a convergência de umidade como identificação do ambiente sinótico dos EEP, no qual se sobressaíram evidências do principal sistema meteorológico responsável pelos EEP95.

\subsection{Ciclo diário do EEP95 (2012 a 2017)}

A estação do SIMEPAR apresentou trinta e quatro EEP95 entre os dias 21/11/2012 a 14/07/2017. A partir da amostra de EEP95, o ciclo diário dos EEP95 foi analisado e encontra-se ilustrado na Fig. 8.

A média das taxas diárias de um EEP95 estimada pela Eq. (6) apresentou um valor de $3,28 \mathrm{~mm} . \mathrm{h}^{-1}$. Este valor está de acordo com resultados de Trenberth et al., 2017, que exploraram várias medidas com relação à duração de eventos de precipitação. Uma das medidas utilizadas por Trenberth et al., 2017 na escala horária é a precipitação excedesse a um certo valor predefinido; valores acima de $2,00 \mathrm{~mm} \cdot \mathrm{h}^{-1}$ são considerados como taxa horária de precipitação forte.
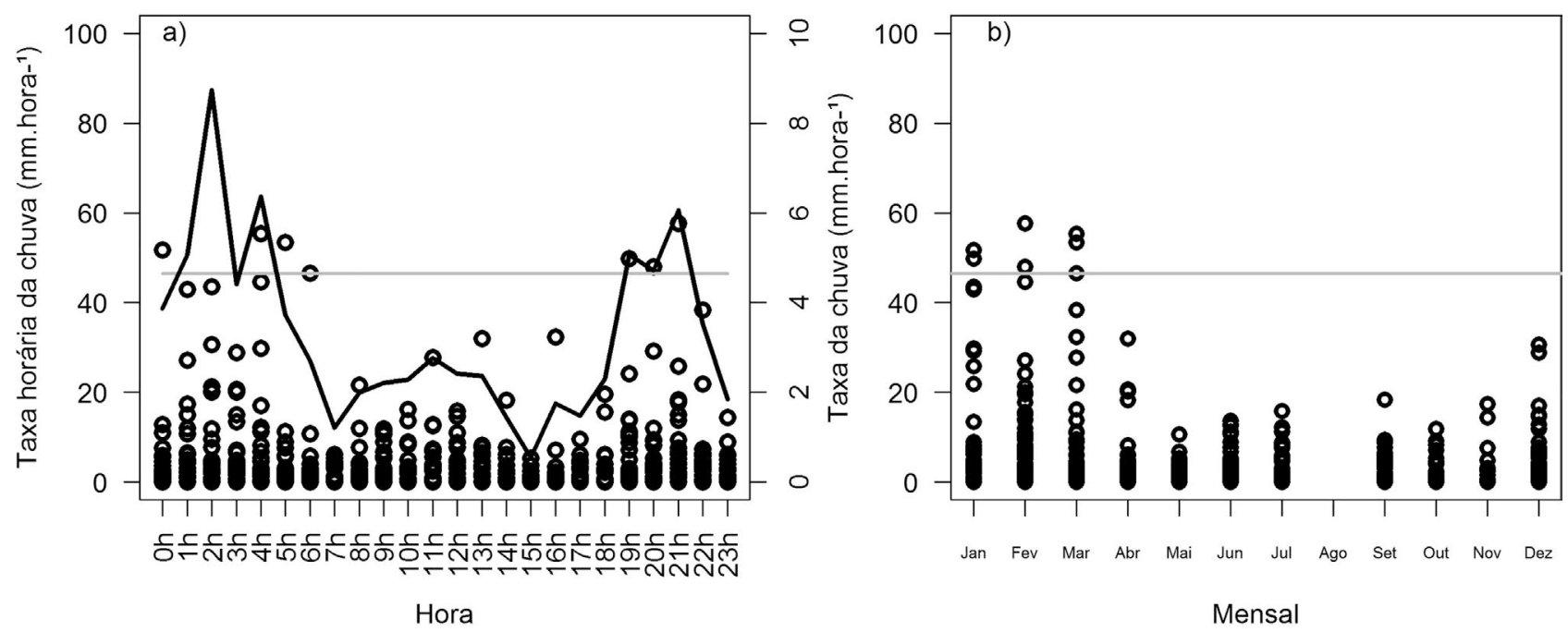

Figura 8 - EEP95 do munícipio de Paranaguá: a) taxa horária de precipitação (linha preta é a média horária de precipitação; linha cinza, o valor do percentil 95) e b) variabilidade mensal da taxa horária. A unidade é $\mathrm{mm} \cdot \mathrm{h}^{-1}$. 
A taxa média diária de um EEP95 também foi estimada para cada mês utilizando a Eq. (6), todos os valores apresentaram-se acima de $2,00 \mathrm{~mm} \cdot \mathrm{h}^{-1}$, e para a estação chuvosa o valor foi $3,87 \mathrm{~mm} . \mathrm{h}^{-1}$. Trenberth et al., 2017 encontraram um valor acima de $3,00 \mathrm{~mm} . \mathrm{h}^{-1}$ para o período de DJF (dezembro a fevereiro) no litoral do Paraná.

A Fig. 8a exibe a taxa horária de precipitação dos EEP95 (círculos abertos) representada pelo eixo principal, no qual se verifica taxas horárias atingindo o percentil 95 (linha cinza, 46,40 mm.dia ${ }^{-1}$ ), observa-se que tal comportamento apresentou-se com mais frequência a partir das 18 $\mathrm{h}$ até as $5 \mathrm{~h}$ da manhã.

Ainda na Fig. 8a, a média de todos os EEP95 para cada hora estimada pela Eq. (7) é ilustrada pela linha preta e os valores referem-se ao eixo secundário. Percebem-se os maiores valores concentrados no início da noite e durante a madrugada, entre $19 \mathrm{~h}$ e $5 \mathrm{~h}$. Os dois máximos de taxa de precipitação média concentraram-se na madrugada ( $2 \mathrm{~h}$ e $4 \mathrm{~h}$ local), com valor de 8,80 e $6,30 \mathrm{~mm} \cdot \mathrm{h}^{-1}$. Em contrapartida, durante o dia as taxas de precipitação diminuem, nos quais entre 7 e $8 \mathrm{~h}, 14$ e $17 \mathrm{~h}$, os valores são inferiores a $2,00 \mathrm{~mm} \cdot \mathrm{h}^{-1}$.

A Fig. 8 b apresenta a variabilidade mensal da taxa de precipitação horária dos EEP95. Verificou-se que taxas horárias atingiram o percentil 95 diário (linha cinza, $46,40 \mathrm{~mm} \cdot \mathrm{dia}^{-1}$ ) apenas durante a estação chuvosa.

\section{Considerações Finais}

Na região estudada, munícipio de Paranaguá, foram analisados trinta anos de dados de precipitação diária da estação do INMET; o percentual de dados ausentes não comprometeu a climatologia, bem como na aplicação da técnica dos quantis. O limiar para um EEP95 diário apresentou o valor de $46,40 \mathrm{~mm} \cdot \mathrm{dia}^{-1}$, sendo possível verificar EEP95 em todos os meses. Os resultados estão de acordo com observado por Teixeira e Satyamurty, 2007. O trimestre chuvoso, de janeiro a março, concentrou cerca de 50\% EEP95. Observaram-se os maiores acumulados diários de precipitação durante o mês de janeiro, apresentando, um dos EEP95, 84,60\% da média mensal.

Apesar dos dados estarem relacionados a uma única localidade, áreas de máxima convergência de umidade destacou o principal sistema meteorológico responsável pelos extremos de precipitação. O ambiente sinótico referente aos EEP95 mostrou evidências da presença da Zona de Convergência do Atlântico Sul (ou ZCOU).

Quanto à variabilidade anual do EEP95, os episódios de ENOS foram, mais uma vez, evidenciados, mostrando a sua influência significativa na frequência de EEP na Região Sul do Brasil. A frequência de EEP95 na estação chuvosa de Paranaguá diminuiu em anos de La Niña e aumentou em anos de El Niño e neutros.

Especificamente para o munícipio de Paranaguá, os resultados da análise da tendência dos EEP95 para o perí- odo entre 1986 e 2016 não mostraram resultados significativos na intensidade e frequência, como evidenciado em alguns estudos para a região Sul do Brasil. A curta série de dados de precipitação pode ter contribuído para tal resultado.

Os dados horários de precipitação do SIMEPAR permitiram observar alguns resultados importantes do ciclo horário dos EEP95; no entanto, limitaram-se a cinco anos. Alguns EEP95 atingiram o valor extremo diário, em apenas $1 \mathrm{~h}$ de registro. Estes eventos ocorreram no início da noite e durante a madrugada, e somente entre os meses de janeiro e março.

Um evento intenso de precipitação que, em geral, ocasionam enxurradas, inundações, além de vendavais, granizo e movimentos de massa, ocorrendo durante a madrugada, na hora em que famílias inteiras descansam, é de fato preocupante. Infelizmente, na maioria das vezes, não é possível sair do local e perdas de vidas entram nas estatísticas dos impactos provocados por extremos climáticos.

O último relatório do IPCC (2014, AR5) dá destaque às atividades de adaptação e mitigação referente aos impactos a extremos climáticos. Uma tentativa em adequação é discutida neste relatório, e encontra-se em implementação em várias regiões do mundo.

Quanto ao sedimento movimentado durante estes eventos e que, possivelmente, serão depositados na baía de Paranaguá, deve-se ter maior atenção entre os meses de janeiro e março, sobretudo em anos de El Niño, que apresenta maior frequência de eventos extremos de precipitação.

\section{Agradecimentos}

Os autores agradecem a CAPES, no âmbito do Programa Nacional de Cooperação Acadêmica - Procad 2013. Projeto n. 88881.068511/2014-01 Edital 071/2013 pela bolsa de Pós-doutorado concedida ao primeiro autor.

\section{Referências}

ALTAMIRANO, R.J.A. Climatologia dos Eventos Chuvosos e Secos Severos, Extremos e muito Extremos usando o Índice de Precipitação Normalizada (SPI) para as Regiões Centro-Oeste, Sudeste e Sul do Brasil. Dissertação de Mestrado, Instituto Nacional de Pesquisas Espaciais, São José dos Campos, 2010.

ALVAREZ, C.A.; STAPE, J.L.; SENTELHAS, P.C.; DE MORAES GONÇALVES, J.L.; SPAROVEK, G. G. Köppen's climate classification map for Brazil, Meteorologische Zeitschrift, v. 22, n. 6, p. 711-728, 2013.

ALVES, J.M.B.; REPELLI, C.A. Variabilidade pluviométrica no setor norte do Nordeste e os eventos El-Niño Oscilação Sul. Revista Brasileira de Meteorologia, v. 7, n. 2, p. 583-592, 1992.

AMORIM, A.C.B.; CHAVES, R.R.; SILVA, C.M.S. Influence of the Tropical Atlantic Ocean's Sea Surface Temperature in 
the Eastern Northeast Brazil Precipitation. Atmospheric and Climate Sciences, v. 4, n. 5, p. 874-883, 2014.

AMORIM, A.C.B.; SILVA, C.M.S.; CHAVES, R.R. Temperatura da superfície do mar do Atlântico Tropical e a precipitação do leste do Nordeste do Brasil. In: XII Simpósio de Recursos Hídricos do Nordeste, Natal, Brasil, 2014.

ANDREOLI, R.V.; KAYANO, M.T. A importância relativa do atlântico tropical sul e pacífico leste na variabilidade de precipitação do Nordeste do Brasil. Revista Brasileira de Meteorologia, v. 22, n. 1, p. 63-74, 2007.

BERRISFORD, P.; DEE, D.P.; POLI, P.; BRUGGE, R.; FIELDING, K.; FUENTES, M.; KÅLLBERG, P.W.; KOBAYASHI, S.; UPPALA, S.; SIMMONS, A. A. The ERAInterim archive Version 2.0. European Centre for Medium Range Weather Forecasts Shinfield Park, Reading, Berkshire RG2 9AX, United Kingdom, 2011.

BOLETINS METEOROLÓGICOS. Paraná: SIMEPAR, 2019. Trimestral.

CAMARGO, R.; MARONE, E. Comportamento do vento de superfície em Pontal do Sul (PR, Brasil): análise preliminar. In: Congresso Latino Americano de Ciências do Mar, Mar del Plata, p. 63-63, 1995.

CARVALHO, L.M.V.; JONES, C.; LIEBMANN, B. Extreme Precipitation Events in Southeastern America and LargeScale Convective Patterns in the South Atlantic Convergence Zone. Journal of Climate, v. 15, n. 17, p. 2377 2394, 2002.

CARVALHO, L.M.V.; JONES, C.; LIEBMANN, B. The South Atlantic convergence zone: intensity, form, persistence, relationships with intraseasonal to interannual activity and extreme rainfall. Journal of Climate, v. 17, n. 1, p. 88-108, 2004.

CAVALCANTI, I.F.A.; KOUSKY, V.E. Frentes frias sobre o Brasil. In: CAVALCANTI, I.F.A.; FERREIRA, N.J.; DIAS, M.A.F.; JUSTI M.G.A. (orgs.), Tempo e Clima no Brasil. São Paulo: Oficina de Textos, p. 135-147, 2009.

CEPED - CENTRO UNIVERSITÁRIO DE ESTUDOS E PESQUISAS SOBRE DESASTRES. S. Atlas Brasileiro de Desastres Naturais 1991 a 2010: Volume Brasil. Universidade Federal de Santa Catarina, 2011.

CHEN, J.; CHUNG, C.H. Representation of global precipitation anomalies using four major climate patterns. Science China Technological Sciences, v. 58, n. 5, p. 927-934, 2015.

COSTA, M.S.; LIMA, K.C.; ANDRADE, M.M.; GONÇALVES, W.A. A. Tendências observadas em extremos de precipitação sobre a região Semiárida do Nordeste do Brasil. Revista Brasileira de Geografia Física, v. 08, n. 5, p. 1321-1334, 2015.

CUNHA, C.L.N.; SCUDELARI, A.C.; ROSMAN, P.C.C. Uso de Técnicas de modelagem para avaliar o transporte de sedimentos no Complexo Estuarino de Paranaguá. In: VIII Congresso sobre Planejamento e Gestão das Zonas Costeiras dos Países de Expressão Portuguesa, Aveiro, Portugal, 2015.

DEE, D.P.; UPPALA, S.M.; SIMMONS, A.J.; BERRISFORD, P.; POLI, P.; KOBAYASHI, S.; ANDRAE, U.; BALMASEDA, M.A.; BALSAMO, G.; BAUER, P.; BECHTOLD, P.; BELJAARS, A.C.M.; VAN DE BERG, L.; BIDLOT, J.; BORMANN, N.; DELSOL, C.; DRAGANI, R.; FUEN-
TES, M.; GEER, A.J.; HAIMBERGER, L.; HEALY, S.B.; HERSBACH, H.; H'OLM, E.V.; ISAKSEN, L.; KALLBERG, P.; K"OHLER, M.; MATRICARDI, M.; MCNALLY, A.P.; MONGE-SANZ, B.M.; MORCRETTE, J.J.; PARK, B.K.; PEUBEY, C.; DE ROSNAY, P.; TAVOLATO, C.; TH’EPAUT, J.N.; VITART, F. F. The ERAInterim reanalysis: configuration and performance of the data assimilation system. Quarterly Journal of the Royal Meteorological Society, v. 137, n. 1, p. 553-597, 2011.

GOCIC, M; TRAJKOVIC, S. Analysis of changes in meteorological variables using Mann-Kendall and Sen's slope estimator statistical tests in Serbia. Global and Planetary Change, v. 100, n. 1, p. 172-182, 2013.

GRIMM, A.M. Clima da Região Sul do Brasil. In: CAVALCANTI, I.F.A.; FERREIRA, N.J.; DIAS, M.A.F.; JUSTI M.G.A. (orgs.), Tempo e Clima no Brasil. São Paulo: Oficina de Textos, p. 259-275, 2009.

GRIMM, A.M.; TEDESCHI, R.G. Enso and extreme rainfall events in South America. Journal of Climate, v. 22, n. 7, p. 1589-1609, 2009.

HASTENRATH, S.; HELLER, L. Dynamics of climatic hazards in Northeast Brazil. Quarterly Journal of the Royal Meteorological Society, v. 103, n. 435, p. 77-92, 1977.

Instituto Brasileiro de Geografia e Estatística. 2014.

Intergovernmental Panel on Climate Change. Fourth Assessment Report: Climate Change (AR4). 2007.

IPCC - Intergovernmental Panel on Climate Change. Impacts, Adaptation, and Vulnerability. Working Group II Fifth Assessment Report (AR5). 2014.

KENDALL, M.G. Rank Correlation Methods. Charles Griffin, London, 120p, 1975.

KODAMA, Y.M. Large-scale common features of sub-tropical precipitation zones (the Baiu Frontal Zone, the SPCZ, and the SACZ). Part I: characteristics of subtropical frontal zones. Journal of the Meteorological Society of Japan, v. 70, n. 4, p. 813-835, 1992.

LANA, P.C.; MARONE, E.; LOPES, R.M.; MACHADO, E.C. The subtropical estuarine complex of Paranaguá Bay, Brazil. In: SEELIGER, U.; KJERFVE, B. Coastal marine ecosystems of Latin America. Berlin: Springer, p. 131$145,2000$.

LIEBMANN, B.; VERA, C.S.; CARVALHO, L.M.V.; CAMELLONI, C.A.; HOERLING, M.P.; ALLURED, D.; BARROS, V.R.; BAEZ, J.; BIDEGAIN, M. M. An observed trend in Central South American precipitation. Journal of Climate, v. 17, n. 22, p. 4357-4367, 2004.

LOPES, F.C.A.; SOUZA, R.M. Análise de um evento extremo e desastre natural nas cidades de Antonina/PR e Morretes/ PR. In: XVII Congresso Brasileiro de Meteorologia, Gramado, Brasil, 2012.

LUCENA, D.B.; SERVAIN, J.; GOMES FILHO, M.F. Rainfall response in Northeast Brazil from ocean climate variability during the second half of the Twentieth Century. Journal of Climate, v. 24, n. 23, p. 6174-6184, 2011.

LUIZ SILVA, W; DERECZYNSKI, C.; CHANG, M.; FREITAS, M; MACHADO, M.J.; TRISTÃO, L.; RUGGER, J. J. Tendências observadas em indicadores de extremos climáticos de temperatura e precipitação no estado do Paraná. Revista Brasileira de Meteorologia, v. 30, n. 2, p. 181-194, 2015. 
MADDEN, R.A.; JULIAN, P.R. Observations of the 40-50 day tropical oscillation - a review. Monthly Weather Review, v. 122 , p. 814-837, 1994.

MANN, H.B. Nonparametric tests against trend. Econometrica, v. 13, n. 1, p. 245-259, 1945.

MINUZZI, R.B.; CARAMORI, P.H. Variabilidade climática sazonal e anual da chuva e veranicos no Estado do Paraná. Revista Ceres, v. 58, n. 5, p. 593-602, 2011.

MOURA, A.D; SHUKLA, J. On the dynamics of droughts in northeast Brazil: observations, theory and numerical experiments with a general circulation model. Journal of the Atmospheric Sciences, v. 38, n. 12, p. 3653-2675, 1981.

OBREGÓN, G.; MARENGO, J.A. Mudanças Climáticas Globais e seus Efeitos sobre a Biodiversidade: Caracterização do Clima no Século XX no Brasil: Tendências de Chuvas e Temperaturas Médias e Extremas. Relatório ${ }^{\circ}$ 2, Ministério do Meio Ambiente, 2007.

OLIVEIRA, A.S. Interações entre Sistemas Frontais na América do Sul e Convecção na Amazônia. INPE-4008TDL/239, 1986.

OLIVEIRA, P.T.; SANTOS E SILVA, C.M.; LIMA, K.C. Climatology and trend analysis of extreme precipitation in subregions of Northeast Brazil. Theoretical and Applied Climatology, v. 130, n. 1-2, p. 77-90, 2016.

OLIVEIRA, P.T.; SILVA, C.M.S.; LIMA, K.C. Linear trend of occurrence and intensity of heavy rainfall events on Northeast Brazil. Atmospheric Science Letters, v. 15, n. 3, p. 172-177, 2014.

PINHEIRO, A.; GRACIANO, R.L.G.; SEVERO, D.L. Tendência das séries temporais de precipitação da Região Sul do Brasil. Revista Brasileira de Meteorologia, v. 28, n. 3, p. 281-290, 2013.

RAO, V.B.; HADA, K. Characteristics of rainfall over Brazil: Annual variations and connections with southern oscillation. Theoretical and Applied Climatology, v. 42, n. 1, p. 81-91, 1990.

REBOITA, M.S.; KRUSCHE, N.; AMBRIZZI, T.; ROCHA, R.P. Entendendo o Tempo e o Clima na América do Sul. Terræ Didatica, v. 8, n. 1, p. 34-50, 2012.

SANTO, C.M.E.; SATYAMURTY, P. Eventos extremos de precipitação na região Sudeste do Brasil e redondezas no período de 1997-2001. In: XII Congresso Brasileiro de Meteorologia, Foz do Iguaçú, Brasil, 2002.
SHIMIZU, M.H.; AMBRIZZI, T.; LIEBMANN, B. Extreme precipitation events and their relationship with ENSO and MJO phases over northern South America. International Journal of Climatology, v. 37, n. 6, p. 2977-2989, 2016.

SILVA DIAS, M.A.F. Dossiê: Clima (Eventos climáticos extremos). Revista USP, v. 1, n. 103, p. 33-40, 2014.

SILVA, F.D.S.; FERREIRA, D.B.; SARMANHO, G.F.; SANTOS, L.S.F.C.; FORTES, L.T.G.; PARENTE, E.G.P.P. Tendência de alterações climáticas da precipitação observadas no Brasil de 1961 a 2008 utilizando dados gradeados. In: XVI Congresso Brasileiro de Meteorologia, Belém, Brasil, 2010.

SOUZA, E.B.; NOBRE, P. Uma revisão do Padrão Dipolo no Atlântico Tropical. Revista Brasileira de Meteorologia, v. 13, n. 1, p. 31-44, 1998.

SOUZA, W.M.; AZEVEDO, P.V.; ARAÚJO, L.E. Classificação da Precipitação Diária e Impactos Decorrentes dos Desastres Associados às Chuvas na Cidade do Recife-PE. Revista Brasileira de Geografia Física, v. 2, n. 1, p. 250268, 2012.

TEIXEIRA, M.S.; SATYAMURTY, P. Dynamical and synoptic characteristics of heavy rainfall episodes in southern Brazil. Monthly Weather Review, v. 135, n. 2, p. 598-617, 2007.

TEXEIRA, M.S.; SATYAMURTY, P. Trends in the Frequency of Intense Precipitation Events in Southern and Southeastern Brazil during 1960-2004. Journal of Climate, v. 24, n. 7, p. 1913-1921, 2011.

TRENBERTH, K.E. The definition of El Niño. Bulletin of the American Meteorogical Society, v. 78, n. 12, p. 27712777, 1997.

TRENBERTH, K.E.; ZHANG, Y.; GEHNE, M. Intermittency in Precipitation: Duration, Frequency, Intensity, and Amounts Using Hourly Data. Journal of Hydrometeorology, v. 18, n. 5, p. 1393-1412, 2017.

WALKER, G.T. Ceará (Brazil) famines and the general air movement. Beitrage zur hysik der freien Atmosphare, v. 14, n. 1, p. 88-93, 1928.

WILKS, D.S. Statistical Methods in the Atmospheric Sciences. Academic Press, London, 648 p, 2006.

License information: This is an open-access article distributed under the terms of the Creative Commons Attribution License (type CC-BY), which permits unrestricted use, distribution and reproduction in any medium, provided the original article is properly cited. 